\section{$\underset{\substack{\text { hommes } \\ \text { \& migrations }}}{ }$}

\section{Hommes \& migrations}

Revue française de référence sur les dynamiques

migratoires

$1303 \mid 2013$

Diasporas marocaines

\title{
Mourad Boudjellal (avec Arnaud Ramsay), Ma
}

mauvaise réputation,

Paris, La Martinière, 2013, 256 p., $18 €$.

\section{Mustapha Harzoune}

\section{(2) OpenEdition}

Journals

Édition électronique

URL : http://journals.openedition.org/hommesmigrations/2616

DOI : 10.4000/hommesmigrations.2616

ISSN : 2262-3353

Éditeur

Musée national de l'histoire de l'immigration

Édition imprimée

Date de publication : 1 juillet 2013

Pagination : 210-211

ISBN : 978-2-919040-23-0

ISSN : 1142-852X

Référence électronique

Mustapha Harzoune, " Mourad Boudjellal (avec Arnaud Ramsay), Ma mauvaise réputation, », Hommes \& migrations [En ligne], 1303 | 2013, mis en ligne le 23 janvier 2014, consulté le 22 septembre 2020.

URL : http://journals.openedition.org/hommesmigrations/2616; DOI : https://doi.org/10.4000/ hommesmigrations.2616

Ce document a été généré automatiquement le 22 septembre 2020.

Tous droits réservés 


\title{
Mourad Boudjellal (avec Arnaud Ramsay), Ma mauvaise réputation,
}

Paris, La Martinière, 2013, 256 p., $18 €$.

\author{
Mustapha Harzoune
}

\section{RÉFÉRENCE}

Mourad Boudjellal (avec Arnaud Ramsay, Ma mauvaise réputation, Paris, La Martinière, 2013, 256 p., $18 €$.

1 Fils d'immigrés aux origines algérienne et arménienne, éditeur de BD, anar tendance Brassens, patron du Rugby Club Toulonnais, homme d'action et d'engagement, Mourad Boudjellal se veut un homme libre, "un vendeur de bonheur", un entrepreneur que "le passé [n]'intéresse pas". Cette autobiographie, qui regorge de bons mots, souvent assassins, esquisse les recompositions de la société française et du monde. Quant aux raisons de s'agacer, elles mollissent, devant la sensibilité d'une grande gueule qui cultive son personnage : "Comme Brassens, j'ai mauvaise réputation. Je le sais. J'en joue. [...] Je suis un sauvage, qui ne s'embarrasse pas de fioritures."

Boudjellal gère le RCT en patron soucieux d'efficacité, d'image, de "rendement", de " buzz", d'anticipation. Adepte du "professionnalisme", il charge le rugby pépère de papa. L'entrepreneur serait un "créateur d'emplois" et "les politiques", des "ratés de l'entreprise" qui "dilapident la monnaie". La petite musique est connue. Pourtant, Mourad Boudjellal, que le syndicalisme "gonfle", revendique "une sensibilité de gauche". Lui qui visite sa maman, Zakia, cinq fois par semaine et qui n'a pas "oublié les moments où je partageais une bouteille de Fanta à quatre avec mes sœurs et frère", ne peut ignorer que la société ne se limite pas aux seuls élus des tranches supérieures d'imposition.

3 À l'instar d'un Driss Chraïbi, il "ne supporte pas la notion de race". "Je me bats pour cette raison contre le système du JIFF, cette règle imposant au club d'avoir dans son effectif [...] $55 \%$ de joueurs issus des filières de formation. [...] Nous véhiculons des idées qui peuvent avoir de l'influence chez les adolescents. Et je n'aime pas le message qui dit à un gamin qu'un étranger 
pourrait prendre sa place [...]. Je suis un habitant de la planète Terre, point. Je me fous de savoir où est né Untel ou Untel, tant qu'il vit les choses avec la même force et passion que moi."

4 La France et le monde ont changé ! Qu'on en finesse, dit Boudjellal, avec la charité des uns, la bonne conscience des autres et le "fonds de commerce" des "touche pas à mon pote", la reconnaissance de l'Autre distillée du bout des lèvres, avec un soupçon d'exotisme (" Tiens, toi tu dois savoir où manger un bon couscous!"), qui vous tient à bonne distance. Fatigué du racisme, subi de père en fils. Ras-le-bol des enfermements religieux : "Je suis arabe mais je ne suis ni musulman, ni chrétien: je suis athée intégriste! Les musulmans m'emmerdent autant que les chrétiens." Exit les simagrées des stars footballistiques ou autres: "Les Nasri ou Benzema représentent trop dans les cités pour ne pas assumer leur rôle. [...] Ils ne se rendent pas compte de leur dimension sociale. La Marseillaise, ce n'est pas mon truc. Mais si j'étais Nasri ou Benzema, je la chanterais, justement pour ces raisons-là." Et de comparer avec les États-Unis : "Il existe là-bas des communautés qui ne parlent pas anglais mais le peuple se sent viscéralement américain, et fier de l'être, avec le drapeau déroulé sur le balcon." À lire Mourad Boudjellal, il serait temps d'accorder les mentalités et les imaginaires à la marche du monde. 